\title{
Attitudes and barriers associated with seasonal influenza vaccination uptake among public health students; a cross- sectional study
}

\author{
Christopher J. Rogers ${ }^{*}$ (D), Kaitlin O. Bahr and Stephanie M. Benjamin
}

\begin{abstract}
Background: Although research has explored influenza vaccination uptake among medical and college students, there is a dearth of research in understanding influenza vaccination uptake and attitudes toward the vaccine among future public health practitioners. Undergraduate public health students represent future public health practitioners who may be a significant educational resource for health information, including the importance of vaccinations.

Methods: This cross-sectional study utilized survey data from 158 undergraduate public health students attending a large public university in Southern California. The survey assessed public health students' attitudes and beliefs towards the seasonal influenza vaccine and seasonal vaccination rates among this population.

Results: Over $88 \%$ of respondents reported having been encouraged to receive the seasonal influenza vaccine, while only $43.0 \%$ reported receipt. Of the students who reported not receiving the vaccine, $49.4 \%$ believed it may give them the flu, 30.4\% believed there may be dangerous side effects, and 28.9\% believed they were not at risk for contracting the flu. Access to health care practitioners (OR: 3.947, 95\% Cl [1.308-11.906]) and social encouragement (OR: 3.139, 95\% Cl [1.447-6.811]) were significantly associated with receipt of the seasonal influenza vaccine.

Conclusion: As public health program curriculum includes information about seasonal influenza vaccination and 68\% of the sample were seniors soon to be exiting the program with an undergraduate degree in public health education, this low seasonal influenza vaccination rate is disturbing. This study may add to the body of data demonstrating how knowledge of the vaccine does not always guarantee vaccine uptake. Results of the current study suggest that it may be beneficial to provide additional information targeted to public health students, aimed at mediating safety concerns and increasing social pressure to assist in improving vaccine acceptance and rates in this population. Maximizing seasonal influenza vaccination uptake by addressing attitudes, barriers and misperceptions may not only improve vaccination rates among public health students, but also in communities served by these future public health practitioners.
\end{abstract}

Keywords: Seasonal influenza vaccine, Public health, College, Education, Vaccine misperceptions

\footnotetext{
* Correspondence: christopher.rogers@csun.edu

Department of Health Sciences, California State University, Northridge, 18111

Nordhoff St., Northridge, CA 91330, USA
}

(c) The Author(s). 2018 Open Access This article is distributed under the terms of the Creative Commons Attribution 4.0 International License (http://creativecommons.org/licenses/by/4.0/), which permits unrestricted use, distribution, and reproduction in any medium, provided you give appropriate credit to the original author(s) and the source, provide a link to the Creative Commons license, and indicate if changes were made. The Creative Commons Public Domain Dedication waiver (http://creativecommons.org/publicdomain/zero/1.0/) applies to the data made available in this article, unless otherwise stated. 


\section{Background}

Influenza is a potentially deadly virus with a seasonal peak between late fall and early spring [1]. In the United States (US), there are approximately 55,000 to 431,000 cases of influenza-associated hospitalizations per year [1]. The Centers for Disease Control and Prevention (CDC) recommends routine annual seasonal influenza vaccinations for all persons 6 months and older with vaccination of particular importance to vulnerable populations, including older adults, young children, pregnant women, and persons with chronic medical conditions, for whom influenza can cause serious illness or death $[1,2]$. Despite these recommendations, US seasonal influenza vaccination rates remain low. It is estimated that only $41 \%$ of adults receive the vaccine, an increase of only $3 \%$ in the past 7 years, falling short of the US Healthy People 2020 goal of $70 \%$ [3, 4].

Health care workers represent an especially vulnerable population when it comes to risk of exposure to the influenza virus. To limit the risk of influenza in this high-risk population, Healthy People 2020 set a goal of $90 \%$ for health care worker vaccination rates, which were estimated to range from 64.3 to $75.2 \%$ across the 2013-14 full season, and the 2014-15 early season [57]. Misconceptions about the vaccine have contributed to low influenza vaccination rates in the US, including among health care workers [5, 7]. Doubting the effectiveness of the vaccine and fear of the vaccine causing illness were the most common reasons given for avoiding vaccination [5, 7]. Physicians, health educators, and other health practitioners are integral to raising community awareness, improving vaccination education, and developing campaigns to increase vaccination uptake among the general population and other health care workers [8-11]. Improving our understanding of the attitudes regarding vaccination as well as factors related to vaccine uptake among health care workers and public health practitioners would be useful in creating more effective educational materials and plans for distribution that may dispel myths about the vaccine within this population. To achieve the goal of improving influenza vaccination rates, it is critical for public health practitioners, including health educators, to be well informed of the benefits and importance of the influenza vaccine.

Several studies have examined seasonal influenza vaccination rates specifically among medical students and residents. US medical student and resident seasonal influenza vaccination rates have been found to range from 48 to $58 \%$ [12-17]. Outside of studies focused on students pursuing medical degrees, there have been few assessing influenza vaccination habits of general college students, with existing research finding vaccination rates from 8 to $30 \%$ [18-24]. Continued research is needed in college students, as influenza has the potential to threaten student populations due to ease of transmission through close social contact and the close proximity of living conditions [25-29]. Although research has explored influenza vaccination uptake among medical students, college students, and health care workers, there is a dearth of research in understanding influenza vaccination uptake and attitudes toward the vaccine among future public health practitioners and future health care workers. Undergraduate public health students represent an important part of the future public health workforce who may be a significant educational resource for health information, including the importance of vaccinations. It is essential to assess vaccination coverage, attitudes, and beliefs among this specific population who may in the future be working with or educating susceptible populations. In addressing the gap, this study assesses undergraduate public health student vaccination rates, attitudes and beliefs about the vaccine and factors impacting vaccination uptake.

\section{Methods \\ Participants, study design, and aim}

Participants were undergraduate students recruited from California State University, Northridge (CSUN), a large diverse public university in Southern California serving 41,548 students [30]. Undergraduates in 2015 were 54\% female, 44\% Hispanic, 53\% low income students, and had a mean age of 23 [30]. This cross-sectional study was implemented in May 2015 using an anonymized self-completed electronic questionnaire. Following institutional review board approval, the questionnaire was emailed to undergraduate students majoring in public health. Eligible participants had to be at least 18 years of age and able to read and write in English. A total of 161 questionnaires were completed and 158 were included in analysis based on the inclusion criteria. Without any incentive or additional encouragement, the response rate was approximately $40 \%$. The current study sought to explore three specific aims.

Aim 1: Assess the prevalence of seasonal influenza vaccination uptake and analyze potential differences in subgroups.

Aim 2: Explore potential barriers to receipt of the seasonal influenza vaccine.

Aim 3: Identify factors associated with reported receipt of the seasonal influenza vaccination.

\section{Measures and instrumentation}

The questionnaire was adapted from a previous 2014 study assessing seasonal influenza vaccination coverage, as well as vaccine attitudes and barriers among undergraduate students at CSUN [24]. The questionnaire was redesigned to be in electronic format and administered through an online survey response collection program. 
These data were then downloaded and recorded for analysis.

Respondents completed a 26-item questionnaire which collected demographic information (including age, sex, race/ethnicity, on/off campus living situation, year of study, and questions relating to inclusion criteria) as well as vaccination history, beliefs about vaccinations, access to health insurance, and sources of vaccine information and vaccine uptake encouragement. Access to health insurance was assessed through three questions related to the use of the campus student health center, last medical check-up, and if the respondent had health insurance. Information on vaccination history was collected by three questions assessing lifetime receipt of influenza vaccination, past 10 -month receipt of influenza vaccination, and location of past 10-month vaccination receipt. Questions related to information received about the vaccine and encouragement to get the influenza vaccine were adapted from a previous study and tailored to fit the studied institution [22]. The sources of encouragement and information included medical practitioners, the student health center, campus flyers/posters, off campus media, and relatives/friends.

Respondents who reported not receiving a vaccination within the past 10 months were asked to complete questions regarding their attitudes toward seasonal influenza vaccination. A Likert scale from $1=$ strongly disagree to $4=$ strongly agree was used to measure attitudes about the seasonal influenza vaccine. The scale was applied to assess the respondent's level of agreement with statements relating to beliefs about vaccination cost, adverse events, importance, risk, and religious or cultural barriers. Questions on attitudes about the vaccine were originally adapted from a previous study conducted on a college campus to examine factors and barriers associated with receipt of the influenza vaccine [22].

\section{Analyses}

Frequency distributions and descriptive statistics were used to assess demographic variables. Associations between demographic factors and vaccination coverage were calculated using t-tests (age) and chi-square tests (race/ethnicity, campus residence, and year of undergraduate study). Statements about beliefs relating to cost, access, and risks of vaccination were truncated to percentage of agreement (either "Agree" or "Strongly Agree") and percentage of disagreement (either "Disagree" or "Strongly Disagree"). The statements about attitudes and beliefs were ranked according to percentage of agreement, and full response means and standard deviations were calculated from all four Likert scale response options. To assess the relationship of factors influencing influenza vaccination and the receipt of the current seasonal influenza vaccine, a logistic regression model was used. Model covariates were selected a priori based on previous study [22, 24]. Demographic covariates were limited due to the small sample size. The multivariable model, adjusting for age, included time elapsed since the most recent visit to a medical provider and sources of vaccine encouragement and information; all of which were regressed on past 10-month influenza vaccine uptake. Analyses were completed using SPSS software version 24 , with a statistical significance level set to 0.05 [31].

\section{Results}

Respondents were 158 undergraduate public health students aged 18 to 54 with a mean age of 22.49 (SD = $3.674) ; 90.5 \%$ identified as female, and the most frequently reported race/ethnicity was Hispanic or Latino (50.3\%), followed by Asian or Pacific Islander (16.6\%). Most of the respondents reported that they were seniors within the public health program (67.7\%) and $96.2 \%$ reported living off campus.

Almost half (48.4\%) of all respondents reported use of the campus student health center within the past 10 months. Over $58 \%$ of respondents reported having seen a medical provider within the past 6 months and $86.6 \%$ reported having some form of health insurance. The majority $(88.4 \%)$ of the respondents reported having been encouraged to receive the seasonal influenza vaccine. The overall reported receipt of the seasonal influenza vaccine was $43.0 \%$ of respondents. Demographic variables stratified by reported receipt of the seasonal influenza vaccine are presented in Table 1. A significant association was found between receipt of the vaccine and when respondents had last visited a medical provider $(p<0.001)$. Age, sex, race/ethnicity, residence, year of undergraduate study, and access to health insurance were not found to be significantly associated with receiving the vaccine.

Statements regarding barriers to receipt of the seasonal influenza vaccine, ranked by percent of agreement, are presented in Table 2. Among students who reported not receiving a seasonal influenza vaccination within the last 10 months: $49.4 \%$ of students agreed with the statement "I believe that as a result of the flu shot I may actually get the flu," $44.9 \%$ of students agreed with the statement "I do not have time to get a flu vaccination," $30.4 \%$ of students agreed with the statement "I believe that vaccines may have dangerous side effects," $28.9 \%$ of students agreed with the statement "I do not believe I am in danger of contracting the flu," $10.7 \%$ of students agreed with the statement "I was not informed that flu vaccines might be important," 9.5\% of students agreed with the statement "I do not know where to receive a flu vaccination," 9.1\% of students agreed with the statement "I do not believe in vaccines for religious or cultural reasons," and $7.7 \%$ of students agreed with the statement 
Table 1 Demographic and health related characteristics of respondents by receipt of seasonal influenza vaccine (within the past 10 months)

\begin{tabular}{|c|c|c|c|}
\hline & $\begin{array}{l}\text { Received the } \\
\text { vaccine } \\
(\%)\end{array}$ & $\begin{array}{l}\text { Did not receive } \\
\text { the vaccine } \\
(\%)\end{array}$ & value ${ }^{*}$ \\
\hline Total & $64(43.0)$ & $84(57.0)$ & - \\
\hline Age mean (SD) & $22.69(3.039)$ & $22.10(2.397)$ & 0.189 \\
\hline \multicolumn{4}{|l|}{ Sex } \\
\hline Male & $5(35.7)$ & $9(64.3)$ & \multirow[t]{2}{*}{0.381} \\
\hline Female & $59(44.0)$ & $75(56.0)$ & \\
\hline \multicolumn{4}{|l|}{ Race/ethnicity } \\
\hline White/Caucasian & $7(38.9)$ & $11(61.1)$ & \multirow[t]{5}{*}{0.199} \\
\hline Black/African American & $1(10.0)$ & $9(90.0)$ & \\
\hline Hispanic/Latino & $38(49.4)$ & $39(50.6)$ & \\
\hline Asian/Pacific Islander & $11(45.8)$ & $13(54.2)$ & \\
\hline Multiracial/Other & $7(38.9)$ & $11(61.1)$ & \\
\hline \multicolumn{4}{|l|}{ Campus residence } \\
\hline On campus & $3(60.0)$ & $2(40.0)$ & \multirow[t]{2}{*}{0.366} \\
\hline Off campus & $60(42.3)$ & $82(57.7)$ & \\
\hline \multicolumn{4}{|l|}{ Year of undergraduate study } \\
\hline Freshman / Sophomore & $10(52.6)$ & $9(47.4)$ & \multirow[t]{3}{*}{0.292} \\
\hline Junior & $8(30.8)$ & $18(69.2)$ & \\
\hline Senior & $46(45.1)$ & $56(54.9)$ & \\
\hline \multicolumn{4}{|l|}{ Health insurance } \\
\hline Yes, I have health insurance & $52(40.9)$ & $75(59.1)$ & \multirow[t]{2}{*}{0.174} \\
\hline No, I do not have health insurance & $11(55.0)$ & $9(45.0)$ & \\
\hline \multicolumn{4}{|l|}{$\begin{array}{l}\text { The last time you went to a medical provider } \\
\text { for treatment or a check-up }\end{array}$} \\
\hline In the past month & $18(54.5)$ & $15(45.5)$ & \multirow[t]{4}{*}{$<0.001$} \\
\hline In the past 6 months & $33(61.1)$ & $21(38.9)$ & \\
\hline Within the past 6 to 12 months & $8(27.6)$ & $21(72.4)$ & \\
\hline More than 1 year / I do not remember the last time & $5(15.6)$ & $27(84.4)$ & \\
\hline
\end{tabular}

* values were calculated using -tests (age) and ${ }^{2}$ tests (sex, race/ethnicity, campus residence, year of undergraduate study, health insurance, and the last time you went to a medical provider for treatment or a check-up.), with a significance level of 0.05

"Vaccines are too expensive for me right now." Percent of agreement did not significantly differ across gender, ethnicity, age, or year of undergraduate study.

Multivariate regression analysis identifying factors associated with receipt of seasonal influenza vaccinations is presented in Table 3. Two factors were identified as significantly associated with receipt of seasonal influenza vaccinations: seeing a medical provider within the last 6 months (OR: 3.947, 95\% CI [1.308-11.906], $p=0.015$ ) and being encouraged by parents, relatives, or friends (OR: $3.139,95 \%$ CI [1.447-6.811], $p=0.004$ ).

\section{Discussion}

The current study explored the seasonal influenza vaccination rate, attitudes and beliefs toward the seasonal influenza vaccine, and factors associated with vaccine uptake among undergraduate students majoring in public health. Results demonstrated that less than half of students surveyed (43\%) reported receipt of the seasonal influenza vaccine. The findings are lower than many of the previous studies which focused on medical students [12-17]. These low uptake results were concerning, particularly considering $68 \%$ of the sample were seniors soon to be exiting the program with an undergraduate degree in public health education. Even though the core curriculum of the public health program covered topics such as seasonal influenza vaccination, studies have demonstrated that knowledge of behaviors do not always guarantee behavior change [22, 32-34]. A 2014 study, at the same university, investigating seasonal influenza vaccination coverage and attitudes and beliefs toward the vaccine among undergraduate students of all majors, found only $20.6 \%$ of students reported 
Table 2 Potential barriers ${ }^{a}$ to receipt of the seasonal influenza vaccine

\begin{tabular}{|c|c|c|c|c|}
\hline & $\mathrm{n}$ & Mean (sd) & $\%$ Agreement & Rank $^{\mathrm{b}}$ \\
\hline \multicolumn{5}{|l|}{ Cost } \\
\hline Vaccines are too expensive for me right now & 78 & $1.58(0.635)$ & 7.7 & 8 \\
\hline \multicolumn{5}{|l|}{ Access } \\
\hline I do not have time to get a flu vaccination & 78 & $2.27(0.963)$ & 44.9 & 2 \\
\hline I do not know where to receive a flu vaccination & 74 & $1.57(0.704)$ & 9.5 & 6 \\
\hline \multicolumn{5}{|l|}{ Safety } \\
\hline I believe that as a result of the flu shot I may actually get the flu & 79 & $2.46(1.023)$ & 49.4 & 1 \\
\hline I believe that vaccines may have dangerous side effects & 79 & $2.05(0.959)$ & 30.4 & 3 \\
\hline \multicolumn{5}{|l|}{ Perceived Importance } \\
\hline I was not informed that flu vaccines might be important & 75 & $1.67(0.741)$ & 10.7 & 5 \\
\hline I do not believe I am in danger of contracting the flu & 76 & $2.12(0.879)$ & 28.9 & 4 \\
\hline \multicolumn{5}{|l|}{ Other } \\
\hline I do not believe in vaccines for religious or cultural reasons & 77 & $1.52(0.736)$ & 9.1 & 7 \\
\hline
\end{tabular}

${ }^{a}$ Barriers were assessed on a Likert scale of agreement from 1 (Strongly Disagree) to 4 (Strongly Agree) and ranked based on percentages of statement agreement (scores of 3-4)

${ }^{\mathrm{b}}$ Ranked in order of percent of agreement with the referenced statements

Note: This table represents responses of students who reported they did not receive the vaccine

receiving the vaccine and nearly $50 \%$ had unsubstantiated fears about vaccination (Benjamin \& Bahr, 2016).

Age was not found to be significantly associated with reported receipt of the seasonal influenza vaccine in the current study. However, a significant association was found between reported receipt of the seasonal influenza vaccine and "The last time you went to a medical provider for treatment or a check-up" $p=0.004$, OR: 3.947, 95\% CI [1.308-11.906]). There was a significantly greater proportion of students reporting receipt of the seasonal influenza vaccine among respondents reporting seeing a medical provider within the past 6 months, compared to those who did not see a medical provider within the past 6 months, $58.6 \%$ to $21.3 \%$ respectively $(p<0.001)$. An explanation could be that students who have seen a medical provider within the past 6 months may be more likely to have health insurance, access to medical services, or are more likely to be encouraged to receive the vaccine by their medical provider. Among those reporting having not received encouragement from parents, relatives, or friends, $73.8 \%$ did not receive the seasonal influenza vaccine. Previous studies in college populations also identified receiving encouragement or information from a medical professional to be associated with vaccination uptake [22, 24]. However, encouragement or information from a medical professional was not found to be significant in multivariate modeling. This could be explained by the fact that the student's curriculum typically covered vaccination recommendations from medical professionals. Since this is already a part of the core curriculum, the weight of influence from receiving encouragement or information from a personal physician or nurse may shift toward other sources. Instead, the model identified receiving encouragement from social groups $(p=0.015, \mathrm{OR}=3.139,95 \% \mathrm{CI}[1.447-6.811])$ to be significant. These findings, confirmed by previous literature, indicate that interventions in this population that consider elements of social influence as well as access to health care, might have a significant impact on vaccination rates [22, 24, 35].

Among students who reported not receiving the seasonal influenza vaccination, a substantial proportion

Table 3 Multivariate analysis of factors associated with reported receipt of the seasonal influenza vaccination (within 10 months preceding data collection)

\begin{tabular}{ll}
\hline & Odds ratio (95\% confidence interval) \\
\hline Encouraged by parents, relatives, or friends & $3.139^{* *}(1.447-6.811)$ \\
Saw a medical provider within the last 6 months & $3.947^{*}(1.308-11.906)$ \\
Encouraged by flyers, TV, or billboards & $1.188(.360-3.924)$ \\
Encouraged by a medical professional & $1.087(.379-3.114)$ \\
Age & $1.108(.954-1.285)$ \\
\hline
\end{tabular}

* $<0.05, * *<0.01, * * * 0.001$

Model controls for age and other covariates 
report safety as a concern. Nearly half of all respondents report a belief that the flu shot may give them the flu, with a third of respondents reporting the belief that there may be dangerous side effects, as well as a third reporting the belief that they are not even at risk for contracting the flu. This is in direct contrast to the information provided to students in the classroom during their time in the program and information provided by the CDC. The CDC clearly identified that an individual is not at risk of contracting influenza from the injected inactivated influenza vaccine and that there is a very remote chance of serious side effects in most populations [36]. Even with the abundance of information available in and out of the classroom, respondents had misconceptions about the safety of vaccinations. The results of the current study suggest that it may be beneficial to provide additional information targeted to public health students, with the goal of mediating safety concerns and potentially increasing vaccination rates in this population. These dialogues could take place in the classroom as a forum discussing the risks of both influenza as well as vaccination. This communication strategy could increase the social pressure to vaccinate while addressing safety concerns. The least frequently reported barriers were cost, not knowing where to get a vaccination, and religious or cultural objections. This suggests that within this population, cost and culture were not prohibitive factors and that students have an adequate knowledge of where to affordably access the influenza vaccinations; therefore, it may be beneficial to focus on providing these students with additional information about why the vaccine is important and safe, in addition to further information on where to receive it.

\section{Limitations}

Study limitations include the use of a convenience sample administered through a department listserv. There is the possibility that students who participated were different from those who did not. Students that participated in the study were likely to be more interested in vaccination, which may have led to an overestimate of vaccination coverage and knowledge than present in non-participants. It is important to note that even with this possible overestimate of coverage, past-year seasonal vaccination coverage rates of $43.0 \%$ in the study population was still substantially lower than the $\mathrm{CDC}$ recommendations of routine annual seasonal influenza vaccinations for all persons 6 months and older. Additionally, without any incentive or additional encouragement, the response rate was approximately $40 \%$, and those responding were predominantly female (90.5\%), Hispanic (50.3\%) and seniors within the public health program (67.7\%). The distribution of gender and race/ ethnicity is representative of the gender distribution and race/ethnicity distribution among students majoring in public health for the same year, (58.1\% Hispanic/Latino and $82.7 \%$ female) [30]. More study participants were seniors $(67.7 \%)$ compared with the approximately the approximately $22.9 \%$ of students that were seniors in the public health program during that same year [30]. Using self-reported data is another potential limitation and reporting bias may have been introduced into this study. Since students could have possibly felt pressured to respond positively to questions regarding vaccination uptake, an effort was made to mitigate overestimation of positive responses by making the questionnaire anonymous and not including sensitive issues. Finally, the issue of influenza vaccine effectiveness and how it may influence the decision making process of potential vaccination recipients was not addressed. It is important to consider that vaccine effectiveness may play a role in the decision making process of those who choose not to vaccinate and may be more pronounced among populations informed about vaccine effectiveness, such as health care workers. Further research is needed to explore if knowledge of vaccine effectiveness impacts vaccination uptake to establish a more comprehensive understanding of why some choose not to vaccinate.

Future studies within this population should consider investigation into whether other factors, such as sex, race, or income, could play a role in the vaccination coverage outcomes. Due to the sample size and low number of students who received the vaccine, the multivariable model was not sufficiently powered to handle additional demographic or other covariates. Because of this, only age and the variables included in the research hypothesis were modeled, since age had been a factor associated in previous literature [24]. Any conclusions drawn from this study must also be considered in light of the small sample size. Further research is needed within this population to determine if these relationships hold in a larger, more generalizable sample.

\section{Conclusion}

Although public health students should be receiving information about vaccinations within their curriculum, it cannot be assumed that they will have positive attitudes and beliefs toward the seasonal influenza vaccine. Additionally, study has shown that knowledge alone may not be enough to increase uptake; attitudes about the value and risk, as well as misperceptions, may play a significant role [7, 37-39]. These study findings support the need for targeted intervention within college public health programs. Interventions that consider elements of social influence as well as access to health care might have an impact on vaccination rates in this population. Specific efforts to educate public health students and address the risks and importance of seasonal influenza 
vaccine uptake may assist in correcting misinformation. Influenza vaccine education strategies that encourage receipt, while incorporating medically accurate information from a nurse or physician, could be integral to correcting attitudinal misperceptions and increasing seasonal influenza vaccination coverage within public health students. Additional information included in curriculum should focus on changing the perceived risk and impact of acquiring seasonal influenza as well as addressing the limited risks from receipt of the vaccination. Many public health students will move into careers in health and medicine and may be the professionals depended upon to promote the vaccine. Maximizing seasonal influenza vaccination uptake in this population by addressing attitudes, barriers, and misperceptions may not only help improve vaccination rates in public health students now, but also in the communities served by these prospective health practitioners.

\section{Abbreviations}

CDC: Centers for Disease Control and Prevention; CSUN: California State University, Northridge; OR: Odds Ratio; SD: Standard Deviation; US: United States

\section{Funding}

This study did not receive any outside funding.

\section{Availability of data and materials}

Data collected and analyzed during the current study are available from the corresponding author on reasonable request.

\section{Authors' contributions}

$\mathrm{SB}$ and $\mathrm{KB}$ designed and conducted the influenza vaccination survey. $C R$ and $\mathrm{KB}$ designed and conducted the study's statistical analyses and SB provided feedback. SB and KB provided a review of the literature. CR drafted the manuscript, and all authors substantially contributed to its contents. All authors read and approved the final manuscript.

\section{Ethics approval and consent to participate}

This study was approved by the California State University, Northridge institutional review board on April 30, 2015 (reference number 1415-178), and all participants provided their written informed consent. Respondents were informed of potential risks and that participation was voluntary, identifying information (excluding age and gender) was not being requested, and that compensation for participation was not being offered.

\section{Consent for publication}

Not applicable.

\section{Competing interests}

The authors declare that they have no competing interests.

\section{Publisher's Note}

Springer Nature remains neutral with regard to jurisdictional claims in published maps and institutional affiliations.

Received: 6 March 2018 Accepted: 16 September 2018 Published online: 20 September 2018

\section{References}

1. Grohskopf LA, Sokolow LZ, Broder KR, Olsen SJ, Karron RA, Jernigan DB, Bresee JS. Prevention and control of seasonal influenza with vaccines recommendations of the advisory committee on immunization practices United States, 2016-17 influenza season. Centers for Disease Control and
Prevention Morbidity and Mortality Weekly Report. MMWR Recomm Rep. 2016;65(5):1-52.

2. Grohskopf LA, Sokolow LZ, Olsen SJ, Bresee JS, Broder KR, Karron RA. Prevention and control of influenza with vaccines: recommendations of the advisory committee on immunization practices, United States, 2015-16 influenza season. Centers for Disease Control and Prevention Morbidity and Mortality Weekly Report. MMWR Morb Mortal Wkly Rep. 2015;64(30):818-25.

3. Centers for Disease Control and Prevention: Flu vaccination coverage, United States, 2015-16 influenza season. https://www.cdc.gov/flu/ fluvaxview/coverage-1516estimates.htm (2017) Accessed 10 Nov 2017.

4. U.S. Department of Health and Human Services, Office of Disease Prevention and Health Promotion: Healthy People 2020 IID-12 Increase the percentage of children and adults who are vaccinated annually against seasonal influenza. https:/www.healthypeople.gov/2020/topics-objectives/ topic/immunization-and-infectious-diseases/objectives; 2018. Accessed 29 Jan 2018.

5. Centers for Disease Control and Prevention: Influenza Vaccination Information for Health Care Workers. https://www.cdc.gov/flu/ healthcareworkers.htm; 2016. Accessed 14 Dec 2017.

6. U.S. Department of Health and Human Services, Office of Disease Prevention and Health Promotion: Healthy People 2020: IID-12.13 Increase the percentage of health care personnel who are vaccinated annually against seasonal influenza. https://www.healthypeople.gov/node/4668/ data_details; 2018. Accessed 29 Jan 2018.

7. Black CL, Yue X, Ball SW, Donahue S, Izrael D, de Perio MA, Laney AS, Lindley MC, Graitcer SB, Lu P. Influenza vaccination coverage among health care personnel-United States, 2013-14 influenza season. Centers for Disease Control and Prevention Morbidity and Mortality Weekly Report. MMWR Morb Mortal Wkly Rep. 2014;63(37):805-11.

8. Painter JE, Sales JM, Pazol K, Grimes T, Wingood GM, DiClemente RJ. Development, theoretical framework, and lessons learned from implementation of a school-based influenza vaccination intervention. Health Promot Pract. 2010;11(Suppl 3):42S-52S.

9. Johnson HH, Glascoff MA, Lovelace K, Bibeau DL, Tyler ET. Assessment of public health educator practice: health educator responsibilities. Health Promot Pract. 2005;6(1):89-96.

10. Balkhy HH, Abolfotouh MA, Al-Hathlool RH, Al-Jumah MA. Awareness, attitudes, and practices related to the swine influenza pandemic among the Saudi public. BMC Infect Dis. 2010;10(1):42.

11. Bouri N, Sell TK, Franco C, Adalja AA, Henderson DA, Hynes NA. Return of epidemic dengue in the United States: implications for the public health practitioner. Public Health Rep. 2012;127(3):259-66.

12. Milunic SL, Quilty JF, Super DM, Noritz GH. Patterns of influenza vaccination among medical students. Infect Cont Hosp Ep. 2010;31(1):85-8.

13. Nafziger DA, Herwaldt LA. Attitudes of internal medicine residents regarding influenza vaccination. Infect Cont Hosp Ep. 2015;15(1):32-5.

14. Toy WC, Janosky JE, Laird SB. Influenza immunization of medical residents: knowledge, attitudes, and behaviors. Am J Infect Control. 2005;33(8):473-5.

15. Ali S, Khakoo R, Fisher M, Hobbs GR. An assessment of influenza vaccination among health profession students. Scand J Infect Dis. 2007;9(9):822-5.

16. Wodi AP, Samy S, Ezeanolue E, Lamour R, Patel R, Budnick LD, Dashefsky B. Influenza vaccine: immunization rates, knowledge, and attitudes of resident physicians in an urban teaching hospital. Infect Cont Hosp Ep. 2016;26(11): 867-73.

17. Lee SI, Aung EM, Chin IS, Hing JW, Mummadi S, Palaniandy GD, Jordan R. Factors affecting medical students' uptake of the 2009 pandemic influenza a (H1N1) vaccine. Influenza Res Treat. 2012; https://doi.org/10.1155/2012/ 753164.

18. Poehling KA, Blocker J, Ip EH, Peters TR, Wolfson M. 2009-2010 seasonal influenza vaccination coverage among college students from 8 universities in North Carolina. J Am Coll Heal. 2012;60(8):541-7.

19. Ramsey MA, Marczinski CA. College students' perceptions of H1N1 flu risk and attitudes toward vaccination. Vaccine. 2011;29(44):7599-601.

20. Nichol KL, D'Heilly S, Ehlinger EP. Influenza vaccination among college and university students: impact on influenza like illness, health care use, and impaired school performance. Arch Pediat Adol Med. 2008;162(12):1113-8.

21. Yang ZJ. Too scared or too capable? Why do college students stay away from the h1n1 vaccine? Risk Anal. 2012;32(10):1703-16.

22. Merrill RM, Kelley TA, Cox E, Layman AB, Layton BJ, Lindsay R. Factors and barriers influencing influenza vaccination among students at Brigham Young University. Med Sci Monitor. 2010;16(2):PH29-34. 
23. Uddin M, Cherkowski GC, Liu G, Zhang J, Monto AS, Aiello AE. Demographic and socioeconomic determinants of influenza vaccination disparities among university students. J Epidemiol Commun H. 2010;64(9):808-13.

24. Benjamin SM, Bahr KO. Barriers associated with seasonal influenza vaccination among college students. Influenza Res Treat. 2016; https://doi. org/10.1155/2016/4248071.

25. Centers for Disease Control and Prevention: Guidance for Responses to Influenza for Institutions of Higher Education during the 2009-2010 Academic Year. https:/www.cdc.gov/h1n1flu/institutions/guidance/ (2010) Accessed 13 Jan 2018.

26. Kar-Purkayastha I, Ingram C, Maguire H, Roche A. The importance of school and social activities in the transmission of influenza a (H1N1) v: England, April-June 2009. Euro surveillance: bulletin Europeen Sur les maladies transmissibles. Eur Commun Dis Bull. 2008;14(33):127-36.

27. Nair H, Brooks WA, Katz M, Roca A, Berkley JA, Madhi SA, Simmerman JM, Gordon A, Sato M, Howie S, et al. Global burden of respiratory infections due to seasonal influenza in young children: a systematic review and metaanalysis. Lancet. 2011;378(9807):1917-30.

28. Thompson WW, Weintraub E, Dhankhar P, Cheng PY, Brammer L, Meltzer MI, Bresee JS, Shay DK. Estimates of US influenza-associated deaths made using four different methods. Influenza Other Resp. 2009;3(1):37-49.

29. Pons VG, Canter J, Dolin R. Influenza a/USSR/77 (H1N1) on a university campus. Am J Epidemiol. 1980;111(1):23-30.

30. California StateUniversity, Northridge: Characteristics of Current Students. https://www.csun.edu/counts/current_undergraduate_students.php (2017). Accessed 20 Dec 2017.

31. Corp IBM. IBM SPSS statistics for windows. In., 24.0 edn. Armonk, NY: IBM Corp; 2016.

32. McKinney WP, Barnas GP. Influenza immunization in the elderly: knowledge and attitudes do not explain physician behavior. Am J Public Health. 1989; 79(10):1422-4

33. Nichol KL. Ten-year durability and success of an organized program to increase influenza and pneumococcal vaccination rates among high-risk adults. Am J Med. 1998;105(5):385-92.

34. Nichol KL, Lofgren RP, Gapinski J. Influenza vaccination: knowledge, attitudes, and behavior among high-risk outpatients. Arch Intern Med. 1992; 152(1):106-10

35. Jerant A, Fiscella K, Tancredi DJ, Franks P. Health insurance is associated with preventive care but not personal health behaviors. J Am Board Fam Med. 2013;26(6):759-67.

36. Centers for Disease Control and Prevention: Inactivated Influenza VIS. https://www.cdc.gov/vaccines/hcp/vis/vis-statements/flu.html (2015) Accessed 28 Dec 2017

37. O'Reilly FW, Cran GW, Stevens AB. Factors affecting influenza vaccine uptake among health care workers. Occup Med-C. 2005;55(6):474-9.

38. Romine WL, Barrow LH, Folk WR. Exploring secondary Students' knowledge and misconceptions about influenza: development, validation, and implementation of a multiple-choice influenza knowledge scale. Int J Sci Educ. 2013;35(11):1874-901

39. Martinello RA, Jones L, Topal JE. Correlation between healthcare workers' knowledge of influenza vaccine and vaccine receipt. Infect Cont Hosp Ep. 2015:24(11):845-7.

Ready to submit your research? Choose BMC and benefit from:

- fast, convenient online submission

- thorough peer review by experienced researchers in your field

- rapid publication on acceptance

- support for research data, including large and complex data types

- gold Open Access which fosters wider collaboration and increased citations

- maximum visibility for your research: over $100 \mathrm{M}$ website views per year

At $\mathrm{BMC}$, research is always in progress.

Learn more biomedcentral.com/submissions 